\title{
Genetic diversity of aflatoxin-producing Aspergillus flavus isolated from selected groundnut growing agro-ecological zones of Uganda
}

Amos Acur ${ }^{1}$, Renée S. Arias², Steven Odongo ${ }^{3}$, Samuel Tuhaise ${ }^{1}$, Joseph Ssekandi ${ }^{1}$, John Adriko ${ }^{1}$, Dennis Muhanguzi ${ }^{3}$, Stephen Buah ${ }^{1 *}$ (D) and Andrew Kiggundu ${ }^{1}$

\begin{abstract}
Background: Groundnut pre- and post-harvest contamination is commonly caused by fungi from the Genus Aspergillus. Aspergillus flavus is the most important of these fungi. It belongs to section Flavi; a group consisting of aflatoxigenic (A. flavus, A. parasiticus and A. nomius) and non-aflatoxigenic (A. oryzae, A. sojae and A. tamarii) fungi. Aflatoxins are food-borne toxic secondary metabolites of Aspergillus species associated with severe hepatic carcinoma and children stuntedness. Despite the well-known public health significance of aflatoxicosis, there is a paucity of information about the prevalence, genetic diversity and population structure of A. flavus in different groundnut growing agroecological zones of Uganda. This cross-sectional study was therefore conducted to fill this knowledge gap.

Results: The overall pre- and post-harvest groundnut contamination rates with A. flavus were 30.0 and $39.2 \%$ respectively. Pre- and post-harvest groundnut contamination rates with A. flavus across AEZs were; 2.5 and 50.0\%; (West Nile), 55.0 and 35.0\% (Lake Kyoga Basin) and 32.5 and 32.5\% (Lake Victoria Basin) respectively. There was no significant difference $\left(X^{2}=2\right.$, $p=0.157)$ in overall pre- and post-harvest groundnut contamination rates with A. flavus and similarly no significant difference $\left(x^{2}=6, p=0.199\right)$ was observed in the pre- and post-harvest contamination of groundnut with $A$. flavus across the three AEZs. The LKB had the highest incidence of aflatoxin-producing Aspergillus isolates while WN had no single Aspergillus isolate with aflatoxin-producing potential. Aspergillus isolates from the pre-harvest groundnut samples had insignificantly higher incidence of aflatoxin production $\left(x^{2}=2.667, p=0.264\right)$ than those from the post-harvest groundnut samples. Overall, A. flavus isolates exhibited moderate level $(92 \%, p=0.02)$ of genetic diversity across the three AEZs and low level $(8 \%, p=0.05)$ of genetic diversity within the individual AEZs. There was a weak positive correlation $(r=0.1241$, $p=0.045$ ) between genetic distance and geographic distance among A. flavus populations in the LKB, suggesting that genetic differentiation in the LKB population might be associated to geographic distance. A very weak positive correlation existed between genetic variation and geographic location in the entire study area $(r=0.01, p=0.471)$, LVB farming system $(r=0.0141, p=0.412)$ and WN farming system $(r=0.02, p=0.478)$. Hierarchical clustering using the unweighted pair group method with arithmetic means (UPGMA) revealed two main clusters of genetically similar $A$. flavus isolates.

(Continued on next page)
\end{abstract}

\footnotetext{
* Correspondence: buahs@yahoo.com

${ }^{1}$ National Agricultural Research Laboratories, P.O. Box 7065, Kampala, Uganda

Full list of author information is available at the end of the article
}

\section{$\triangle B M C$}

(c) The Author(s). 2020 Open Access This article is licensed under a Creative Commons Attribution 4.0 International License, which permits use, sharing, adaptation, distribution and reproduction in any medium or format, as long as you give appropriate credit to the original author(s) and the source, provide a link to the Creative Commons licence, and indicate if changes were made. The images or other third party material in this article are included in the article's Creative Commons licence, unless indicated otherwise in a credit line to the material. If material is not included in the article's Creative Commons licence and your intended use is not permitted by statutory regulation or exceeds the permitted use, you will need to obtain permission directly from the copyright holder. To view a copy of this licence, visit http://creativecommons.org/licenses/by/4.0/ The Creative Commons Public Domain Dedication waiver (http://creativecommons.org/publicdomain/zero/1.0/) applies to the data made available in this article, unless otherwise stated in a credit line to the data. 
(Continued from previous page)

Conclusions: These findings provide evidence that genetic differentiation in A. flavus populations is independent of geographic distance. This information can be valuable in the development of a suitable biocontrol management strategy of aflatoxin-producing $A$. flavus.

Keywords: Mycotoxins, Secondary metabolites, Aspergillus species and agro-ecological zone

\section{Background}

Groundnut (Arachis hypogaea L.), is a major legume grown on approximately 25 million hectares of the semiarid tropical and sub-tropical regions of the world between latitudes $40{ }^{\circ} \mathrm{N}$ and $40{ }^{\circ} \mathrm{S}$. The global annual production is estimated at 36 million tons [1]. Groundnut is the second most important legume in Uganda after the common bean (Phaseolus vulgaris) [2]. The consumption of groundnut in Uganda is in either of the following forms: roasted seeds, groundnut stew, groundnut paste and sometimes raw seed cake is used as animal feed.

Despite its importance as a food and cash crop, groundnut faces production and export constraints from mycotoxin accumulation that results from contamination by Aspergillus species favoured by the tropical climate experienced in Uganda [3]. Mycotoxins are secondary metabolites produced during fungal metabolism in response to environmental stress. The toxins are secreted in defence, virulence or cell signalling [4]. These secondary metabolites are stable compounds that cannot be degraded by any ordinary cooking temperature or food processing procedures [5-7]. When these compounds are ingested, they cause problems to both human and livestock health in the form of acute illness, chronic illness, instant death or immunosuppression among others [5]. In most cases, the effects of mycotoxins are manifested much later after exposure [6].

Human and livestock exposure to mycotoxins in developing countries result from over-reliance on a single staple food crop which is normally grown only once a year [8]. Therefore, this food commodity is kept much longer under storage in order to prolong its availability awaiting new harvest in the succeeding year. Since most storage facilities in developing countries are improvised structures, a great proportion of the stored crop produce get contaminated by Aspergillus species, resulting into changes in taste, colour, odour and nutritional value of food and feeds [9].

The economic losses due to Aspergillus contamination may reach $100 \%$ when the presence of aflatoxins beyond acceptable levels results in produce rejection [10]. Acute aflatoxicosis is often as a result of subject exposure to high doses of aflatoxins resulting into instant death, whereas chronic aflatoxicosis is due to exposure to sublethal doses over a long period of time [11]. Chronic aflatoxicosis results in liver cancer, immune suppression and teratogenicity among other complications [11]. This problem is a common occurrence in developing countries like Uganda where farmers have inadequate food storage facilities and poor food handling practices [12]. In addition, in developing countries, no strict regulatory measures exist against high levels of aflatoxins in food and feedstuffs, leading to frequent episodes of aflatoxicosis and often death in humans [13].

The ability of fungal species to produce aflatoxins is strain-specific and it is controlled by aflatoxin biosynthesis gene cluster, consisting of aflR, aflS, aflP, aflQ, aflD, aflM and aflO genes [14]. Sequence variability in this aflatoxin biosynthesis gene cluster has always been useful in deducing diversity in aflatoxigenic Aspergillus flavus species [15]. At the moment, no scientific reports have been published about the genetic diversity of indigenous A. flavus population in Uganda. The objective of the present study was therefore to assess the contamination rates of groundnut with major Aspergillus species and to examine the genetic diversity of indigenous $A$. flavus isolated from groundnut in six representative districts within the agro-ecological zones (AEZs) of Uganda using InDel markers located within the aflatoxin biosynthesis gene cluster.

\section{Results}

The dominant fungal species contaminating groundnut in Uganda is not well understood due to the complexity in the underlying causes including geographical and genotypic factors. Two hundred and forty groundnut samples were collected from the three AEZs of Uganda for fungal isolation and characterisation. In total, 231 Aspergillus spp. isolates were identified from the groundnut samples collected (Table 1). The isolates comprised of A. flavus, A. parasiticus and Aspergillus section Nigri. Typically, more than one Aspergillus species were found co-existing on $70.0 \%(168 / 240)$ of the total groundnut samples collected and on $61.0 \%(73 / 120)$ of the postharvest groundnut samples. Aspergillus flavus was the most abundant, both as S- and L-strains, whereas $A$. parasiticus was the least abundant species observed (Table 1). The three Aspergillus species were distributed throughout the AEZs surveyed with LKB having the highest abundance of $A$. flavus and WN with the least (Table 1). Aspergillus section Nigri was most abundant in the LVB and least abundant in WN (Table 1). 
Table 1 Aspergillus species and strains identified by AEZs

\begin{tabular}{lllll}
\hline Agro-ecological zone & $\begin{array}{l}\text { A. flavus } \\
\text { (S strain) } \\
n=88\end{array}$ & $\begin{array}{l}\text { A. flavus } \\
(\text { L strain) } \\
n=46\end{array}$ & A. parasiticus $n=3$ & $\begin{array}{l}\text { Aspergillus } \\
\text { section Nigri } \\
n=94\end{array}$ \\
\hline West Nile & $10(11.36 \%)$ & $2(4.35 \%)$ & $1(33.33 \%)$ & $18(19.15 \%)$ \\
L. Victoria basin & $36(40.91 \%)$ & $14(30.43 \%)$ & $1(33.33 \%)$ & $46(48.94 \%)$ \\
L. Kyoga basin & $42(47.73 \%)$ & $30(65.22 \%)$ & $1(33.33 \%)$ & $30(31.91 \%)$ \\
$\begin{array}{l}\text { Total } \\
(\boldsymbol{N}=\mathbf{2 3 1})\end{array}$ & $\mathbf{8 8 ( 3 8 . 1 0 \% )}$ & $\mathbf{4 6 ( 1 9 . 9 1 \% )}$ & $\mathbf{3 ( 1 . 3 0 \% )}$ & $\mathbf{9 4}(\mathbf{4 0 . 6 9 \% )}$ \\
\hline
\end{tabular}

Aspergillus parasiticus was least abundant in equal proportions across the three AEZs (Table 1). However, the abundance and distribution of each species never differed significantly across AEZs $(p=0.165)$.

Overall, $34.6 \%(83 / 240)$ of the groundnut samples collected had Aspergillus. The post-harvest groundnut samples were more contaminated than the pre-harvest groundnut samples with the contamination frequencies of 39.2 and $30.0 \%$ respectively. Generally, Lake Kyoga basin mixed-farming system had the highest number of groundnut samples contaminated with Aspergillus and WN farming system had the lowest number of groundnut samples contaminated with Aspergillus (Table 2). At the pre-harvest level, LKB had the highest Aspergillus contamination frequency whereas the WN farming system had the lowest (Table 2). The post-harvest contamination frequency was highest in $\mathrm{WN}$ farming system while the LVB farming system had the lowest (Table 2). Although the contamination proportions (both pre- and post-harvest) varied in the three AEZs (Table 2), the Pearson's Chi square test revealed no significant difference in Aspergillus contamination among the three $\operatorname{AEZs}\left(X^{2}=6, p=0.199\right)$.

Examination of the aflatoxin production capacity of selected Aspergillus isolates showed that LKB had the highest incidence of isolates with aflatoxin-producing potential whereas WN had no single isolate capable of producing aflatoxins (Table 3). The incidence of aflatoxin production was higher among Aspergillus isolated from the pre-harvest groundnut samples of LKB origin and from the post-harvest groundnut samples of LVB origin (Table 3). In general, the incidence of aflatoxin production by Aspergillus isolates from the pre-harvest groundnut samples was insignificantly higher $\left(x^{2}=2.667\right.$, $p=0.264)$ than that of Aspergillus isolates from the postharvest groundnut samples across AEZs (Table 3).

Out of the 137 Aspergillus section Flavi isolates (A. flavus and $A$. parasiticus), 96 representative isolates were fingerprinted using 25 InDel-primed PCR markers at 65 loci of the aflatoxin biosynthesis gene cluster. After the clonal correction, only 67 out of 96 isolates had unique allele scores generated from 16 out of the 25 InDel markers and at 24 loci out of the total 65 loci of the gene cluster genotyped. Fingerprint data of these 67 isolates were then used in the subsequent statistical analyses. Based on the Mantel tests of correlation between matrices of geographic and genetic distances, there was no significant isolation by distance for the entire study area $(r=0.01, p=0.471)$ (Fig. 1a). When each AEZ was examined separately, isolation by distance between the $A$. flavus populations was detected in the LKB, with a weak positive correlation $(r=0.1241$, $p=0.045$ ) (Fig. 1c) between the geographical distance and genetic distance. Similarly, there was also a weak genetic divergence of 0.0154 in the LKB due to geographic distance (Fig. 1c). The rest of the AEZs had insignificant positive correlations between the geographic distances and genetic distances (Fig. $1 \mathrm{~b}$ and d).

The dendrogram generated using UPGMA algorithm revealed two major clusters that corresponded to the amplification patterns within the aflatoxin biosynthesis gene cluster of each isolate displayed in a capillary electrophoregram. From this electrophoregram, isolates with the most amplified portions within their aflatoxin biosynthesis gene cluster were in cluster I while isolates with the least amplified portions within the aflatoxin biosynthesis gene cluster were in cluster II (Fig. 2). The result from total aflatoxins analysis using an ELISA kit on the presentative

Table 2 Proportions of groundnut samples contaminated by Aspergillus at pre-and post-harvest

\begin{tabular}{llll}
\hline Agro-ecological zone & $\begin{array}{l}\text { Pre-harvest contamination } \\
(\mathrm{n}=40)\end{array}$ & $\begin{array}{l}\text { Post-harvest contamination } \\
(n=40)\end{array}$ & $\begin{array}{l}\text { Overall contamination } \\
(n=80)\end{array}$ \\
\hline West Nile & $1(2.50 \%)$ & $20(50.00 \%)$ & $21(26.25 \%)$ \\
L. Victoria basin & $13(32.50 \%)$ & $13(32.50 \%)$ & $26(32.50 \%)$ \\
L. Kyoga basin & $22(55.00 \%)$ & $14(35.00 \%)$ & $36(45.00 \%)$ \\
Total $(\boldsymbol{N}=\mathbf{1 2 0})$ & $\mathbf{3 6}(\mathbf{3 0 . 0 0 \% )}$ & $\mathbf{4 7}(\mathbf{3 9 . 1 7 \% )}$ & $\mathbf{8 3 ( 3 4 . 5 8 \% )}$ \\
\hline
\end{tabular}


Table 3 Aflatoxin production potential of selected Aspergillus section Flavi isolates from three agro-ecological zones at pre- and post-harvest stages

\begin{tabular}{|c|c|c|c|c|c|}
\hline AEZ & Isolate & Sample type & Sample status & Total aflatoxins (ppb) & Incidence (\%) \\
\hline Lake Kyoga Basin & SS-1468-LKB & Pre-harvest & Positive & 169 & $83.33 \%$ \\
\hline \multirow[t]{5}{*}{$n=6$} & SS-1513-LKB & Pre-harvest & Positive & 364 & \\
\hline & SS-1607-LKB & Pre-harvest & Positive & 121 & \\
\hline & SS-1463-LKB & Pre-harvest & Positive & 841 & \\
\hline & SS-1485-LKB & Pre-harvest & Positive & 1429 & \\
\hline & SS-1517-LKB & Pre-harvest & Negative & 0 & $16.67 \%$ \\
\hline \multirow[t]{6}{*}{$n=6$} & SS-1546-LKB & Post-harvest & Positive & 0.42 & $16.67 \%$ \\
\hline & LS-1478-LKB & Post-harvest & Negative & 0 & $83.33 \%$ \\
\hline & LS-1603-LKB & Post-harvest & Negative & 0 & \\
\hline & LS 1605-LKB & Post-harvest & Negative & 0 & \\
\hline & LS-1554-LKB & Post-harvest & Negative & 0 & \\
\hline & SS-1473-LKB & Post-harvest & Negative & 0 & \\
\hline Lake Victoria Basin & SS-1525-LVB & Pre-harvest & Positive & 598 & $16.67 \%$ \\
\hline \multirow[t]{5}{*}{$n=6$} & SS-1453-LVB & Pre-harvest & Negative & 0 & $83.33 \%$ \\
\hline & SS-1524-LVB & Pre-harvest & Negative & 0 & \\
\hline & SS-1520-LVB & Pre-harvest & Negative & 0 & \\
\hline & SS-1549-LVB & Pre-harvest & Negative & 0 & \\
\hline & SS-1458-LVB & Pre-harvest & Negative & 0 & \\
\hline \multirow[t]{6}{*}{$n=6$} & SS-1629-LVB & Post-harvest & Positive & 9 & $50.00 \%$ \\
\hline & SS-1526-LVB & Post-harvest & Positive & 648 & \\
\hline & SS-1527-LVB & Post-harvest & Positive & 175 & \\
\hline & SS-1453-LVB & Post-harvest & Negative & 0 & $50.00 \%$ \\
\hline & SS-1536-LVB & Post-harvest & Negative & 0 & \\
\hline & SS-1626-LVB & Post-harvest & Negative & 0 & \\
\hline \multirow{6}{*}{$\begin{array}{l}\text { West Nile } \\
n=6\end{array}$} & LS-1509-WN & Pre-harvest & Negative & 0 & $100 \%$ \\
\hline & LS-1454-WN & Pre-harvest & Negative & 0 & \\
\hline & SS-1511-WN & Pre-harvest & Negative & 0 & \\
\hline & SS-1486-WN & Pre-harvest & Negative & 0 & \\
\hline & SS-1496-WN & Pre-harvest & Negative & 0 & \\
\hline & SS-1627-WN & Pre-harvest & Negative & 0 & \\
\hline \multirow[t]{6}{*}{$n=6$} & SS-1568-WN & Post-harvest & Negative & 0 & $100 \%$ \\
\hline & SS-1536-WN & Post-harvest & Negative & 0 & \\
\hline & SS-1456-WN & Post-harvest & Negative & 0 & \\
\hline & SS-1493-WN & Post-harvest & Negative & 0 & \\
\hline & SS-1457-WN & Post-harvest & Negative & 0 & \\
\hline & SS-1487-WN & Post-harvest & Negative & 0 & \\
\hline$N=36$ & & & & & \\
\hline
\end{tabular}

isolates picked from each AEZ confirmed that isolates in cluster I were aflatoxigenic while those in cluster II were non-aflatoxigenic.

Analysis of molecular variance reflected that variation within populations and variation between regions (AEZs) were significant and accounted for genetic variation of 92 and $8 \%$ respectively (Table 4 ). Therefore, most of the observed genetic differentiation was due to variation within populations.

\section{Discussion}

Considerable achievements have been made in controlling aflatoxins contamination of agricultural products following the discovery that aflatoxins are extremely 

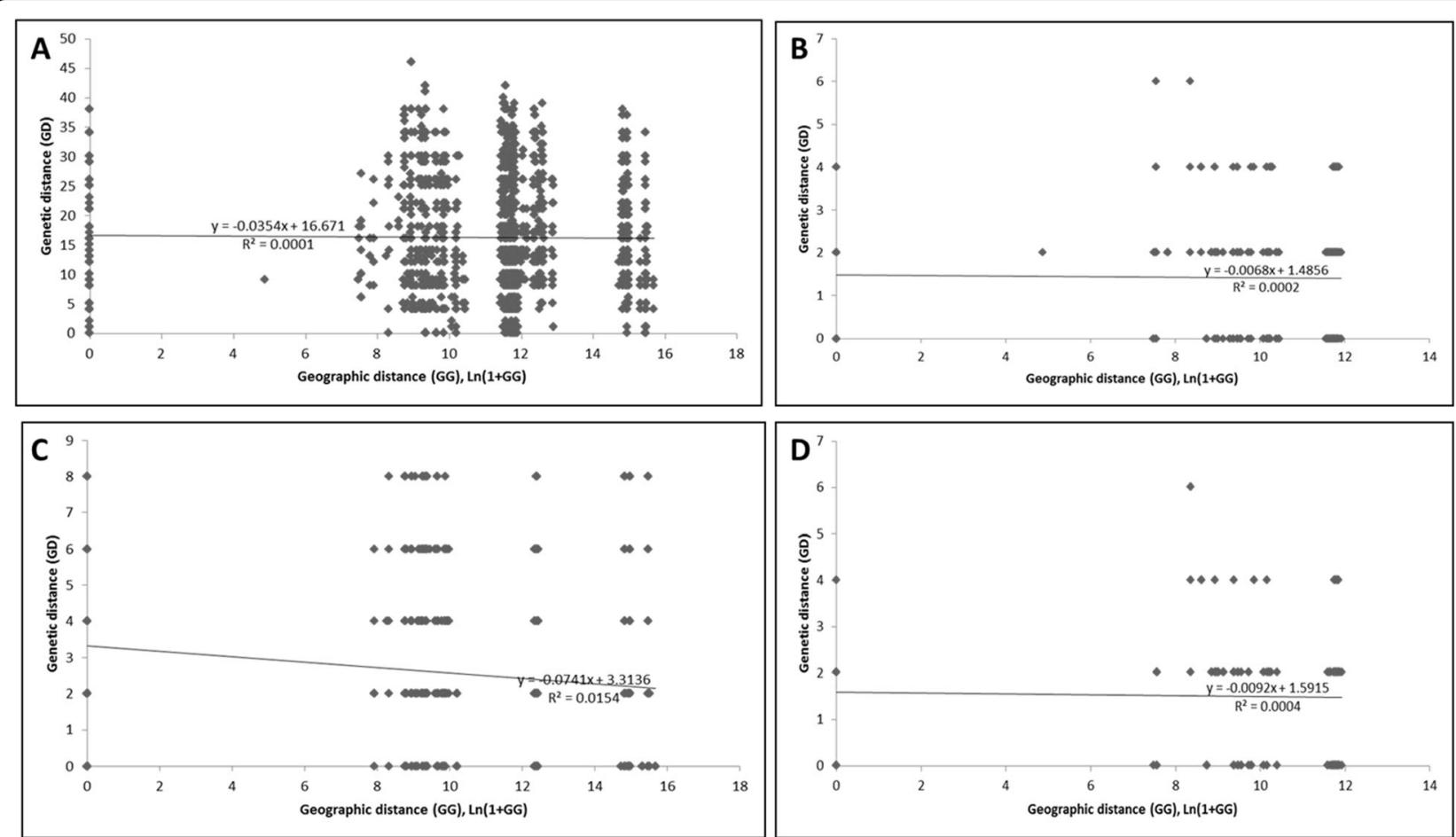

Fig. 1 Isolation by distance plots. Genetic distance plotted as a function of geographic distance for the entire study area $(p=0.471, r=0.01)(\mathbf{a})$, the Lake Victoria basin farming system $(p=0.412, r=0.0141)(\mathbf{b})$, the Lake Kyoga basin farming system $(p=0.045, r=0.1241)$ (c) and the West Nile farming system $(p=0.474, r=0.02)$ (d). The bold line represents the line of best fit to the plotted data and $r$ values represent the correlation between geographic and genetic distances matrices assessed using the Mantel test

toxic secondary metabolites to both humans and livestock [16, 17]. This study sought to elucidate the diversity of Aspergillus species contaminating groundnuts collected at pre- and post-harvest stages from three different agroecologies of Uganda. Due to seasonal variations in the different agroecologies, it was impossible to collect all samples from the study areas at the same time. In addition to sample collection constraints, we identified Aspergillus species and strains using stereoscopic microscopy, which is still considered a standard practice for microbial identification, but were unable to confirm the species identities using molecular tools.

In this study, Aspergillus section Flavi and Aspergillus section Nigri were the most abundant Aspergillus species encountered in groundnut samples. This finding concurs with that from a study done by Rathod \& Naikade [18]. Most of the Aspergillus species in section Nigri are of great importance in the industrial manufacture of amylases, lipases, citric acid and gluconic acid [19]. However, they cause food deterioration with subsequent production of mycotoxins; ochratoxin A (OTA), ochratoxin B, fumonisin B2, fumonisin B4, and secalonic acids, A, D, F as the major natural products toxic to humans and animals [20]. Ochratoxin A has been reported to be a nephrotoxic compound causing renal cancer [21]. Groundnut contamination with A. flavus and some species from Aspergillus section Nigri is also known for lowering the germination ability of groundnut seeds under storage [22], and the longer the storage duration, the higher the frequency of contamination by Aspergillus species [23]. Thus, reduction in seed quality due to Aspergillus contamination results in poor seed germination ability, low productivity and hence food insecurity.

In general, presence of $A$. flavus as the most abundant and distributed fungal contaminant of groundnut is consistent with previous reports by Klich [12]; Bhatnagar et al. [10]; and Cotty \& Jaime [24] . Groundnut contamination by Aspergillus species originates at the pre-harvest stage as was previously noted by Ligia et al. [25] in their study. This is because Aspergillus species are well adapted in the soil as conidia, hyphae and sclerotia, which are in direct contact with groundnut pods [26, 27]. Other abiotic factors like drought stress, a common experience in the LKB mixed farming system could be responsible for high susceptibility of groundnut at pre-harvest stage $[17,18$, 28].

One of the interesting findings from this study was the lower Aspergillus contamination rates in WN farming system. This observation could be due to a higher altitude in WN farming system that is associated with relatively lower temperatures and relative humidity compared to the other AEZs. Cropping system and climate could be 


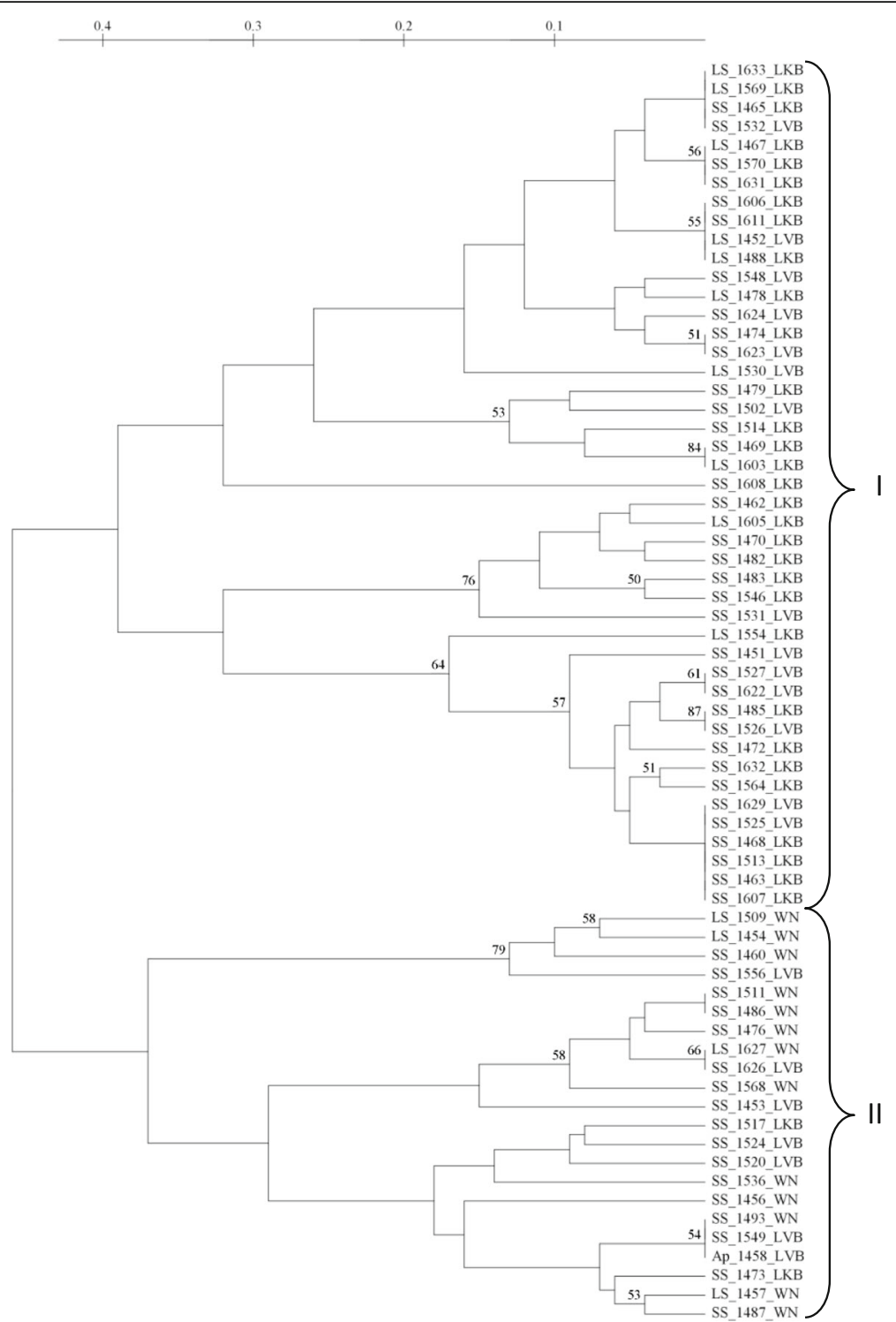

Fig. 2 Dendrogram of genetic relationships among 67 Aspergillus isolates. The result from a fingerprint data based on InDel markers used in genotyping 67 isolates collected from three agro-ecological zones using the UPGMA algorithm and the genetic distances at 1000 replications. The initials SS and LS represent $S$ and L strains of A. flavus respectively while AP represents A. parasiticus. Clusters I and II comprise of aflatoxigenic and non-aflatoxigenic isolates respectively

Table 4 AMOVA summary that describes the proportion of genetic variance in Aspergillus section Flavi isolates at different hierarchical levels

\begin{tabular}{lllllll}
\hline Source of variation & df & SS & MS & Est. var & $\%$ & $P$-value \\
\hline Among regions & 2 & 3.418 & 1.709 & 0.089 & $8 \%$ & 0.05 \\
Among populations & 1 & 0.17 & 0.17 & 0 & $0 \%$ & 0.927 \\
Within populations & 63 & 65.487 & 1.039 & 1.039 & $92 \%$ & 0.02 \\
Total & 66 & 69.075 & & 1.128 & $100 \%$ & \\
\hline
\end{tabular}

responsible for Aspergillus species distribution pattern and abundance within these AEZs that are far apart and with different climatic conditions as was noted by Horn \& Dorner [29]. No significant statistical difference existed between pre-harvest and post-harvest contamination levels of groundnut with Aspergillus species across AEZs. This could be due to common pre- and postharvest handling methods employed as previously noted by Dube \& Maphosa [30].

When $A$. flavus isolates from the pre- and post-harvest groundnut samples were tested and incidences for aflatoxins production compared, no significant difference in aflatoxin-production ability was observed across AEZs. 
This is in agreement with Torres et al. [31], confirming that both the pre- and post-harvest groundnut can habour aflatoxin-producing Aspergillus provided there are suitable environmental conditions for Aspergillus growth and aflatoxins production.

Analysis of molecular variance (AMOVA) revealed that variation within populations was most responsible for genetic differentiation as compared to variation among populations and variation among regions (AEZs). Genetic variations in A. flavus within populations could be due to different cropping practices employed in each field from which samples were taken [30-32]. Furthermore, the AMOVA results suggest the existence of low genetic differentiation among regions (AEZs). This could be evidence of gene flow between the different AEZs as a result of human activities like trade and transportation of Aspergillus-contaminated groundnuts between AEZs. Another reason could be based on differential competition strategies employed by different genotypes of Aspergillus section Flavi to survive in diverse environments. For example, an isolate which is highly competitive during sporulation may exhibit dominance over a wide geographical region during multiple reproductive cycles although it is a poor competitor during crop infection. All these are likely to have important impacts on the $A$. flavus population structure.

On the other hand, genotypes that are dominant within the host tissues are better adapted to surviving in an AEZ having harsh environmental conditions that do not favour mechanisms for sporulation, dispersal and secondary infections [33]. Insignificant isolation by distance in the entire study area implies that there was gene flow leading to low genetic differentiation among AEZs while significant isolation by distance observed in the Lake Kyoga basin farming system is an indication that nearby populations in this AEZ were genetically more similar than expected by chance, and genetic differences increases linearly with geographic distances. This particular AEZ is semi-arid and therefore most strains of $A$. flavus in this region are adapted to living within the plant host tissues as a means of adapting to unfavourable environmental conditions. They, therefore, tend to remain localized in particular geographical locations within the AEZ since sporulation and dispersal that could have limited genetic isolation by distance are limited by harsh environmental conditions [34].

The variations between regions (AEZs) shown by the AMOVA results could have been as a result of differences in the period that Aspergillus was in association with groundnut in each AEZ. Temporal differences in the stages at which Aspergillus is in association with groundnuts, either at pre- or post-harvest could also be responsible for the observed population differentiation among regions. Each AEZ has its unique colonization stages for groundnut-associated Aspergillus and genetic adaptations undergone by the Aspergillus for its host plant differ with the stage of growth of the plant. This means AEZs may also differ in temporal stages of association of Aspergillus with groundnuts right from the initial colonization till the development of correlated spatial genetic structure over time. Two major clades are due to the insertion/deletion in the aflatoxin biosynthesis gene cluster of the fingerprinted A. flavus isolates. Since this gene cluster has a set of conserved genes that regulate the biosynthesis and secretion of aflatoxins by the fungus, any alteration in their sequences either by insertion or deletion can lead to nonaflatoxigenicity $[35,36]$.

\section{Conclusion}

Aspergillus section Flavi and Aspergillus section Nigri are the most abundant species contaminating groundnuts in Uganda. They co-exist in groundnuts posing serious health risks to both humans and animals. Since contamination starts at the pre-harvest stage due to drought stress, early planting should be emphasized so that there is enough rain to take the plants through their growth and development. In case of unexpected drought, simple irrigation technologies should be adopted to meet the water demands of the plants, especially during pod development stage.

The genetic diversity of $A$. flavus in various AEZs provides a gene pool of potential value for application in biocontrol. This can be exploited to reduce the prevalence of aflatoxigenic fungi in the environment through competitive exclusion mechanism. From the results of genetic diversity analyses of $A$. flavus populations in the three selected AEZs, any non-aflatoxigenic strain of $A$. flavus can be selected as a biocontrol strain since there is no significant population differentiation by geographical distance. This strategy has been proven to be successful and it is already being applied in many countries that intensively produce groundnut, like the US [17]. Furthermore, the identified aflatoxigenic strains of $A$. flavus can be used to screen for resistance to Aspergillus colonization and subsequent aflatoxins production in different crop cultivars during a crop breeding programme.

Future studies could investigate the role of spatial and temporal variations on the genetic structure of A.flavus populations associated with groundnuts and also validate recently reported molecular markers by Hussain et al. [36] for detecting afltoxigenic strains of $A$. flavus on groundnuts collected from various environments.

\section{Methods}

\section{Sample collection}

There were three levels to the sampling design: (i) AEZs, (ii) districts within AEZ, and (iii) individual fields within the districts (Fig. 3). Not all sites were sampled during 


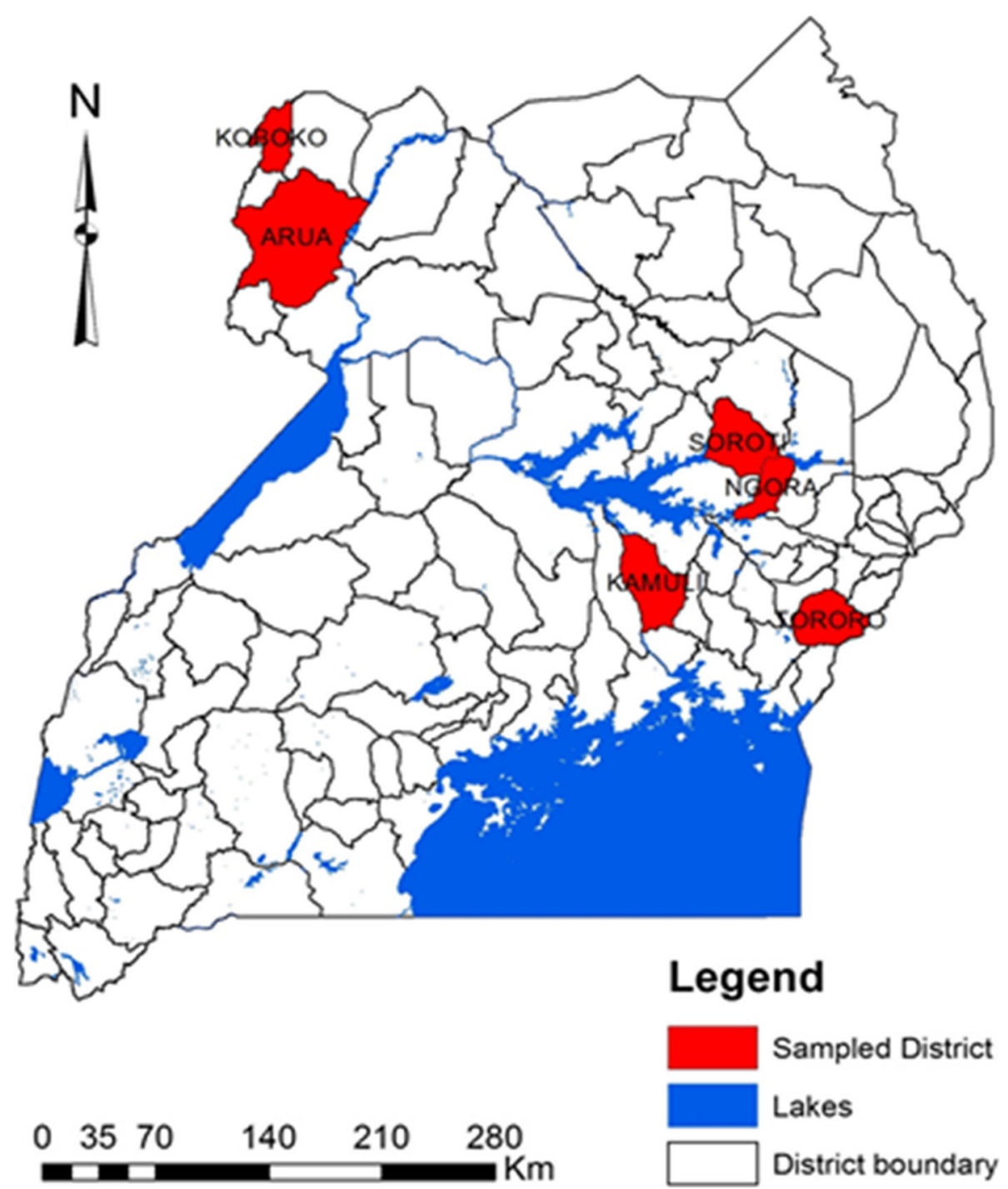

Fig. 3 Location and zonal context of selected agro-ecological zones. Six districts were sampled from the entire study area, two districts from each agro-ecological zone to obtain groundnuts for Aspergillus isolation. Source: Uganda Bureau of Statistics [37]

the same cropping season. Agro-ecological zones were selected to represent a range of agro-ecologies in Uganda known for groundnut production according to the Uganda Bureau of Statistics report, 2014. Two districts from each groundnut-growing AEZ were randomly selected and surveyed. The selected major groundnutgrowing AEZs of Uganda included: West Nile farming system (WN), high altitude districts (districts of Arua and Koboko), Lake Kyoga basin mixed farming system (LKB), low altitude districts (districts of Soroti and Ngora) and Lake Victoria basin farming system (LVB), mid-altitude districts (districts of Tororo and Kamuli) (Fig. 3).

Households and groundnut fields in selected AEZs were surveyed for sample collection. Forty groundnut samples, consisting of 20 field samples and 20 storage samples, were collected from each selected district. For field collection, a quadrat measuring $1 \mathrm{~m} \times 1 \mathrm{~m}$ was thrown randomly at five different sampling points and any distance $\geq 10 \mathrm{~m}$ between sampling points was considered. Three groundnut stands were pulled from each sampling point and handpicked on the same day of sampling. Extra care was taken to sort out pods that were damaged by soil fauna and later clean pods packed in a paper bag. The groundnut pods were sun-dried for a week, disinfected using a $0.5 \%(\mathrm{v} / \mathrm{v})$ sodium hypochlorite solution, hand shelled and stored at $4{ }^{\circ} \mathrm{C}$ until fungal isolation according to Mutegi et al. [38].

Sub-samples of storage shelled groundnuts were collected randomly from each bag or container from the top, middle and bottom using a sampling probe and later mixed to form a composite sample. About $250 \mathrm{~g}$ of 
the composite sample were drawn and packed in a sterile paper bag for fungal isolation. Unshelled groundnuts were taken only once from each storage bag or container and packed for laboratory analysis following the method of Ndungu et al. [39].

\section{Isolation of Aspergillus species from groundnut seeds}

Aspergillus species were isolated at National Peanut Research Laboratory, Dawson, Georgia, USA. A selective growth medium, modified dichloran Rose Bengal (MDRB) was used for isolation of Aspergillus section Flavi [29]. The MDRB medium is composed of $10 \mathrm{~g} / \mathrm{L}$ dextrose, 2.5 $\mathrm{g} / \mathrm{L}$ peptone, $1.0 \mathrm{~g} / \mathrm{L}$ di-potassium phosphate $\left(\mathrm{KH}_{2} \mathrm{PO}_{4}\right)$, $0.5 \mathrm{~g} / \mathrm{L}$ magnesium sulphate heptahydrate $\left(\mathrm{MgSO}_{4} .7 \mathrm{H}_{2} \mathrm{O}\right)$, $0.5 \mathrm{~g} / \mathrm{L}$ yeast extract, $20 \mathrm{~g} / \mathrm{L}$ agar, $0.5 \mathrm{~mL}$ of $0.05 \%(\mathrm{w} / \mathrm{v})$ Rose Bengal stock solution in acetone, adjusted to $1 \mathrm{~L}$ with distilled water and later modified with $0.8 \mathrm{mg} / \mathrm{L}$ dichloran. After sterilization, $30 \mathrm{mg} / \mathrm{L}$ streptomycin and $0.15 \mathrm{mg} / \mathrm{L}$ tetracycline were added to the medium. Twenty seeds per sample were put into separate sterile $50 \mathrm{~mL}$ falcon tubes and $15 \mathrm{~mL}$ sterile distilled water added to each. The seeds were washed by shaking in a pulverizing machine, KLECO (Visalia, California, USA) for $2 \mathrm{~min}$ [40]. Thereafter, $50 \mu \mathrm{L}$ of each of the suspensions was separately spread plated onto MDRB medium [41], followed by incubation at $37^{\circ} \mathrm{C}$ for 3 days. Colonies of Aspergillus present per sample were counted, and contamination incidence (\%) for each AEZ was deduced by counting the number of sample plates having $\geq 25$ colonies of aflatoxin-producing Aspergillus species in each AEZ, $(n=120)$ according to Horn \& Dorner [42]. In a biosafety cabinet, a stereo microscope and a flame sterilized needle were used to isolate conidia from the colonies of interest in each culture plate. Direct isolation of pure colonies of A. flavus and A. parasiticus from the MDRB culture plates was based on the size of conidiophores, vesicles, conidia and on the colour of conidial heads [43]. Colonies of A. flavus appear yellow-green to grey-green while those of $A$. parasiticus are dark green according to Christensen [43]. The fully grown A. flavus colonies are of two strains, the S strain and the $\mathrm{L}$ strain. The $\mathrm{S}$ strain is characterised by numerous sclerotia $<400 \mu \mathrm{m}$ in diameter whereas the $\mathrm{L}$ strain produces fewer sclerotia $>400 \mu \mathrm{m}$ in diameter [44]. Using a stereo microscope, the conidia from a single conidiophore were then picked and transferred onto freshly prepared plates of MDRB medium. In order to obtain a single colony from the picked conidia, streaking was done by successively turning the media plate in a right-angle manner in an attempt to adequately disperse the individual conidium at the extreme end of the streak. After three days of incubation at $37^{\circ} \mathrm{C}$, hyphal tips from single colonies were picked using a flamed scalpel and transferred into Czapek Dox agar (OXOID Ltd., Hampshire, England) slants for identification and storage.

\section{Aspergillus species and strain identification}

Twelve-day old pure cultures of Aspergillus grown on Czapek Dox agar at $30^{\circ} \mathrm{C}$ were morphologically characterized based on the distinguishing features for each morphotype as described above. Different species and strains were identified in accordance with Diba et al. [45], and comparison to reference cultures in the collection at National Peanut Research Laboratory, Dawson, GA, USA. Each isolate was derived from a sample and in some cases, two or more isolates would be derived from a single sample on condition that the colony characteristics showed different morphotypes; L- or S- strain $(A$. flavus) or A. parasiticus.

\section{Quantification of total aflatoxin from A. flavus mycelia}

This was done using the MaxSignal Total Aflatoxin ELISA Test kit (Bioo Scientific Corporation, Austin, Texas, USA). Representative A. flavus isolates consisting of 18 each from pre-harvest and from the post-harvest groundnut samples were randomly picked from each AEZ for total aflatoxin quantification. Each of the isolate was grown on potato dextrose agar at $37^{\circ} \mathrm{C}$ for 7 days. Mycelia were extracted and ground for $3 \mathrm{~min}$ in a $3 \mathrm{ml}$ extraction solution $(70 \% \mathrm{v} / \mathrm{v}$, methanol/water) using a sterile mortar and pestle. The ground samples were allowed to settle and the top layer of the extract filtered through a Whatman \#1 filter paper. The resultant filtrate was treated with the kit's reagents following manufacturer's instructions. A microwell reader fitted with a $450 \mathrm{~nm}$ filter was used to read the optical density of the reaction mixture in each microwell. A standard curve was constructed using ELISA absorbance readings of the total aflatoxin standards $(0,0.02,0.06$, $0.2,0.6$ and $1.5 \mathrm{ng} / \mathrm{mL}$ ) to determine aflatoxin concentrations in $\mathrm{ppb}$. Absorbance readings and concentrations of the standard solutions were entered into a Microsoft Excel 2016 spreadsheet, and a standard curve was generated (Fig. 4). From this standard curve, concentrations of aflatoxins in corresponding samples were calculated using the equation of the line; $\mathrm{y}=-0.0719 \mathrm{x}+2.09(\mathrm{y}=$ optical density and $\mathrm{x}=$ aflatoxins concentration).

\section{Genomic DNA extraction and quantification}

Genomic DNA from the Aspergillus flavus isolates was extracted at National Peanut Research Laboratory, Georgia, USA, using Qiagen DNeasy Plant kit (QIAGEN, Hilden, Germany). Sterile disposable plastic loops were used to harvest 3 loopful of spores from the culture slants and loaded into each sample tube. Following the manufacturer's instructions, a $500 \mu \mathrm{l}$ clear lysate was pipetted into a $2 \mathrm{ml}$ eppendorf tube and later loaded into a QIAcube robot (QIAGEN, Hilden, Germany). 


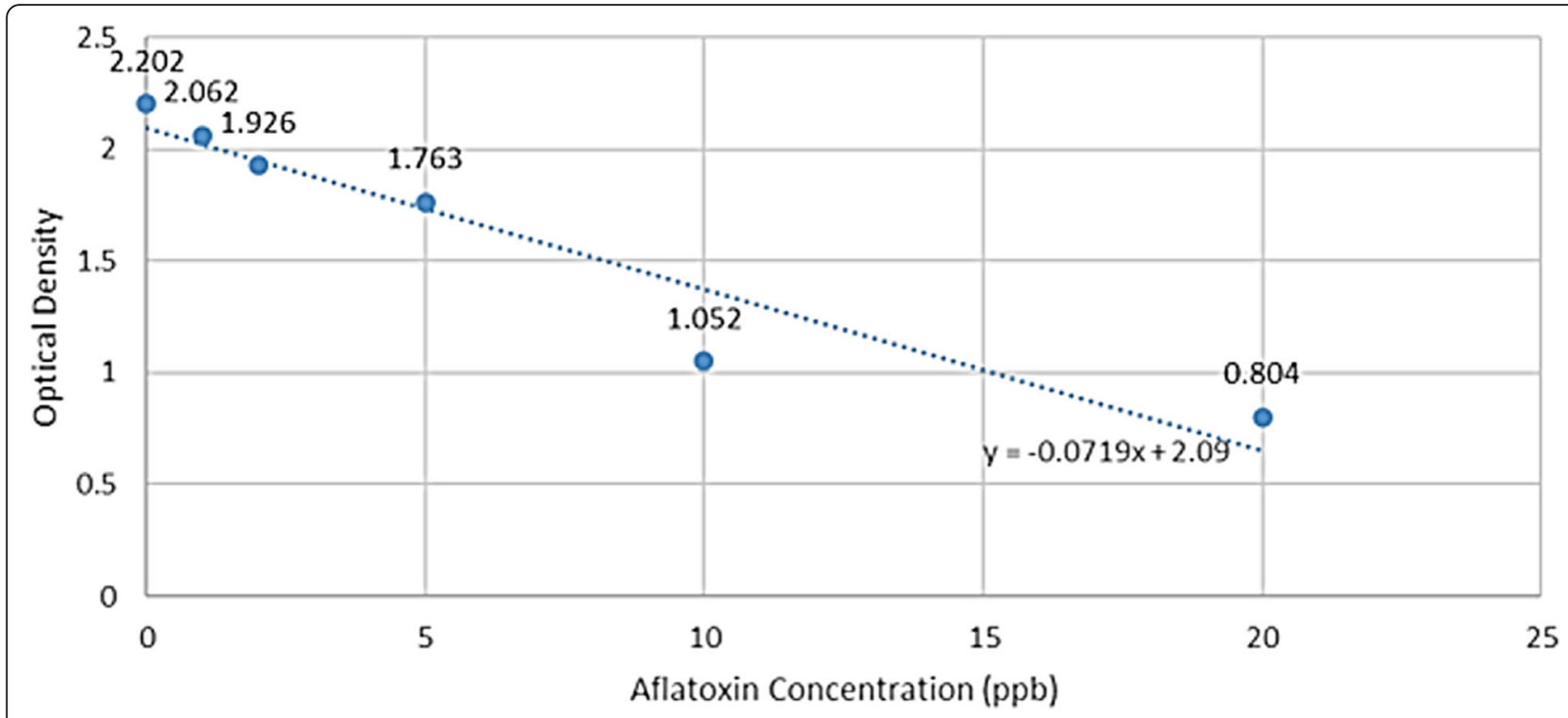

Fig. 4 Standard curve for determination of aflatoxins concentration. The equation of the line was used to calculate the corresponding concentrations of aflatoxins in each sample based on the absorbance readings

The concentration of the eluted DNA was determined using a Nanodrop ND 2000 spectrophotometer (Thermo Fisher Scientific, Wilmington, DE, USA).

\section{Genotyping of Aspergillus flavus isolates}

Primers that were previously developed by Faustinelli et al. [40] to detect insertions-deletions (InDels) within the aflatoxin-biosynthesis cluster of Aspergillus were used in this study for the genetic fingerprinting of the Aspergillus isolates (Table 5). Since deletions/insertions in this gene cluster are associated with aflatoxin production [35], clustering of isolates were deduced from the shared deletions/insertions patterns that correspond to aflatoxigenicity or non-aflatoxigenicity.

The forward primers were tailed with a $5^{\prime}$-CAGTTT TCCCAGTCACGAC-3' sequence and labelled with 6carboxyfluorescein (6-FAM). The reverse primers were tailed with $5^{\prime}$-GTTT-3' sequence to promote nontemplate adenylation [46]. Amplifications were performed using $10 \mathrm{ng}$ of DNA and Titanium Taq

Table 5 Primer pairs that were used in the amplification of the aflatoxin biosynthesis gene [40]

\begin{tabular}{|c|c|c|c|}
\hline Marker & Forward $5^{\prime} \rightarrow 3^{\prime}$ & Reverse $5^{\prime} \rightarrow 3^{\prime}$ & Amplicon size (bp) \\
\hline AFLC01 & CCGACCTCACGACGCATTAT & CCGGCTAGCTTCAACAGACG & $140-370$ \\
\hline AFLC02 & GGTTGGCGGATTGAGAGGTA & GGAGATCAGCCGAGAAGACA & $100-296$ \\
\hline AFLC03 & TCCGCCGAGAGCCATAATAG & GGATGCTGACACCTCGATAG & $120-160$ \\
\hline AFLC07 & GTCAGCAAGAGGAGCCTTCA & GGTCACGGAGATCCTCCATA & 159-404 \\
\hline AFLC08 & CGCCAGCACGGAGATCGAAT & CGTCTCCTCAGGCGGTCTAT & 224-399 \\
\hline AFLC12 & CGCAAGGAGCTCGACCAATA & TTCAGCTCAGCGACGAGAGT & $241-360$ \\
\hline AFLC13 & TCGGTTCAATGCTCGAACAC & TCCAACCTTCGGCCTAGTCT & $140-410$ \\
\hline AFLC15 & GCTCTACAGGCTGATTCAAG & TCGACAGTCCGACAATATGC & $204-370$ \\
\hline AFLC16 & ATCGCAGCGGAAGCTTGGAA & AGTCTCGGACTCCGGTGACA & $145-410$ \\
\hline AFLC17 & GCACAACTCGTACAGCTATC & TCTAAGTGCGAGGCAACGAA & $125-390$ \\
\hline AFLC18 & GGCAGCCAGACCAAGGAATA & CCTTCTCGTAGCCGCTCATC & $130-400$ \\
\hline AFLC19 & ACAGGACCGCACGGATCAAT & AGGAGCGGATGTCGAAGTCT & $260-491$ \\
\hline AFLC20 & GCCTAGCGCTCCATTCTCAG & CCATCGTATCCGGCTCTATC & $120-370$ \\
\hline AFLC21 & TACCTTACTCCGCTAAGCAG & GCGGTCACCTACCAATGAAT & $150-368$ \\
\hline AFLC22 & TTCGCAGGAGTGTAGCCAAG & GTTGGAACACGCTCCATAGG & $120-371$ \\
\hline AFLC24 & GAACGAGATAACGGCTGCAT & ATCAATCCACGGACCGTTGT & $100-430$ \\
\hline
\end{tabular}


polymerase (Clontech) in $5 \mu \mathrm{l}$ reactions as described by Arias et al. [47]. The labelled PCR amplicons were analyzed using an ABI 3730XL DNA analyzer and data were processed by GeneMapper v 4.0 (Applied Biosystems, Foster City, California, USA).

\section{Data analysis}

The GenStat Discovery Edition 14 (2002) for windows (VSN International Ltd., Rothamsted Experimental Station, UK) software was used for data analysis. The Chi-square test and One-Way analysis of variance (ANOVA) were used to compare the frequencies of groundnut contamination with Aspergillus species and to determine the relative abundance of isolated Aspergillus species and strains at pre- and post-harvest stages respectively. Allele sizes observed as relative fluorescence units from the electropherogram were converted to binary data, where the presence of an amplicon of any size was scored as ' 1 ' whereas its absence was scored as ' 0 '. The fingerprint data for all the samples were corrected for clonality by removing isolates sharing the same InDel profiles at all loci from the data. Analyses like population pair-wise Fst values and allele frequencies were performed on isolates' alleles data in order to establish whether the sample size for each AEZ is adequate to be used in subsequent statistical analyses. After these, our analyses were restricted to unique isolates identified from the fingerprint data and to AEZs for which $A$. flavus isolates were available. Analysis of molecular variance was carried out using the program Arlequin version 3.5 for estimation of variance components and partition of the within and among population variance. In addition, isolation by distance (IBD) was assessed using the Mantel test that plots the genetic distance against geographic distance (log-transformed) for the entire study area and within districts using the program GenAIEx 6.5b. In both analyses, significance was assessed by conducting 999 permutations. During these analyses, sixteen InDel loci were used to identify genetic structure in $A$. flavus populations. Allele frequencies were calculated for A. flavus within each AEZ and georeferenced. Allele frequencies were standardized by the lowest value and natural log-transformed while retaining zero values. Relationships among the isolates based on InDel data were determined through unweighted pair group method with arithmetic mean (UPGMA) with 1000 bootstrap replications [16], using TREECON for Windows version $1.3 \mathrm{~b}$.

\section{Abbreviations}

AEZs : Agro-ecological zones; AMOVA: Analysis of molecular variance; ANOVA: Analysis of variance; DNA: Deoxyribonucleic acid; InDel: Insertion /deletion; MDRB: Modified dichloran Rose Bengal; PCoA: Principal Coordinate analysis; PCR: Polymerase Chain Reaction; ppb: Parts per billion; RNA: Ribonucleic acid; RNAi: Ribonucleic acid interference; UBOS: Uganda Bureau of Statistics

\section{Acknowledgements}

The authors would like to thank Valerie Orner who trained the first author at National Peanut Research Laboratories, Dawson, Georgia, USA. We are also grateful to Dr. Michael Hillary Otim of National Crops Resources Research Institute (NaCRRI) - Uganda and Dr. Francis Onyilo of Muni University, Uganda for playing a mentoring role to the first author and providing valuable initial review respectively.

\section{Authors' contributions}

The study was designed by AA together with AK and RA. DM, SO and SB supervised the overall study. AA, RA, ST, JS and SB participated in data collection, data analysis and interpretation. AA drafted the first manuscript that was reviewed and corrected by JA before all other co-authors made significant contributions. All authors read and approved the manuscript.

\section{Funding}

Data collection and subsequent analyses were funded by the NARO under the PEARL Project, sponsored by the Bill \& Melinda Gates Foundation. Travel and accommodation for the first author at the National Peanut Research Laboratories, USA was funded by the US Department of Agriculture Agricultural Research Services. The funders didn't have any role in the designing of the study, data collection, analysis and interpretation of data as well as in writing the manuscript.

\section{Availability of data and materials}

The datasets generated during and/or analysed during the current study are available from the corresponding author on reasonable request.

\section{Ethics approval and consent to participate}

This is a case report that does not involve human or animal subjects and therefore no ethical approvals are required.

\section{Consent for publication}

Not applicable.

\section{Competing interests}

The authors declare that they have no competing interests.

\section{Author details}

${ }^{1}$ National Agricultural Research Laboratories, P.O. Box 7065, Kampala, Uganda. ${ }^{2}$ National Peanut Research Laboratories, P.O. Box 509, 1011 Forrester Drive, S.E, Dawson, GA 39842, USA. ${ }^{3}$ College of Veterinary Medicine Animal Resources and Biosecurity, Makerere University, P.O. Box 7062, Kampala, Uganda.

Received: 22 June 2020 Accepted: 26 July 2020

Published online: 14 August 2020

\section{References}

1. Chen X, Li H, Pandey MK, Yang Q, Wang X, Garg V, et al. Draft genome of the peanut A-genome progenitor ( Arachis duranensis) provides insights into geocarpy, oil biosynthesis, and allergens. Proc Natl Acad Sci. 2016;(2): 201600899 Available from: http://www.pnas.org/lookup/doi/10.1073/pnas.16 00899113 .

2. Okello DK, Biruma M, Deom CM. Overview of groundnuts research in Uganda : Past, present and future. 2010;9(39):6448-59.

3. Bhat RV, Vasanthi S. Food Safety in Food Security and Food Trade Mycotoxin Food Saf Risk Dev Countries IFPRI Br. 2003;3:1-2.

4. Valiante V. The Cell Wall Integrity Signaling Pathway and Its Involvement in Secondary Metabolite Production. J Fungi. 2017;3(4):68 Available from: http://www.mdpi.com/2309-608X/3/4/68.

5. Mohsenzadeh MS, Hedayati N, Riahi-Zanjani B, Karimi G. Immunosuppression following dietary aflatoxin B1 exposure: a review of the existing evidence. Toxin Rev. 2016;35(3-4):121-7.

6. Ismaiel AA, Papenbrock J. Mycotoxins: Producing Fungi and Mechanisms of Phytotoxicity; 2015. p. 492-537.

7. Ryu D, Bianchini A, Bullerman LB. Effects of processing on mycotoxins. Stewart Postharvest Rev. 2008:4(6):1-7.

8. Bryden WL. Mycotoxins in the food chain: human health implications. Asia Pac J Clin Nutr. 2007;16(SUPPL.1):95-101. 
9. Perrone G, Susca A, Cozzi G, Ehrlich K, Varga J, Frisvad JC, et al. Biodiversity of Aspergillus species in some important agricultural products. Stud Mycol. 2007;59:53-66 Available from: http://linkinghub.elsevier.com/retrieve/pii/ S0166061614601755.

10. Bhatnagar-Mathur P, Sunkara S, Bhatnagar-Panwar M, Waliyar F, Sharma KK Biotechnological advances for combating Aspergillus flavus and aflatoxin contamination in crops. Plant Sci. 2015;234:119-32 Available from: https:// doi.org/10.1016/j.plantsci.2015.02.009.

11. Kumar P, Mahato DK, Kamle M, Mohanta TK, Kang SG. Aflatoxins: A global concern for food safety, human health and their management. Front Microbiol. 2017;7(JAN):1-10.

12. Klich MA. Aspergillus flavus: the major producer of aflatoxin. Mol Plant Pathol. 2007:8(6):713-22

13. Horn BW, Moore GG, Carbone I. Sexual reproduction in Aspergillus flavus. Mycologia. 2009;101(3):423-9.

14. Qureshi YE. Pakistan Veterinary Journal. Animals. 2013;8318(2):85-92 Available from: http://www.pvi.com.pk/pdf-files/31 3/192-194.pdf.

15. Okoth S, De Boevre M, Vidal A, Di Mavungu JD, Landschoot S, Kyallo M, et al. Genetic and toxigenic variability within Aspergillus flavus population isolated from maize in two diverse environments in Kenya. Front Microbiol. 2018:9(JAN):1-14.

16. Mahmoud MA, El-Samawaty AMA, Yassin MA, Abd El-Aziz ARM. Genetic diversity analysis of Aspergillus flavus isolates from plants and air by ISSR markers. Genet Mol Res. 2016;15(2):1-9.

17. Dorner JW. Biological control of aflatoxin contamination of crops. J Toxicol Toxin Rev. 2004;23(2-3):425-50.

18. Rathod LR, SM Naikade, MR Mote. Biodiversity of Aspergillus spp . on groundnut seeds. 2015;(December):47-50.

19. Varga J, Frisvad JC, Kocsubé S, Brankovics B, Tóth B, Szigeti G, et al. New and revisited species in Aspergillus section Nigri Extrolite analysis. 2011:1-17.

20. Hoof JB, Frisvad JC. Diversity in secondary metabolites including Mycotoxins from strains of Aspergillus section Nigri isolated from raw cashew nuts from Benin. West Africa. 2016:1-14

21. Abarca ML, Accensi F, Cano J, Cabañes F. Taxonomy and significance of black Aspergilli. [Taxonomía y significado de los aspergillus negros]. Antonie Van Leeuwenhoek [Internet]. 2004;86(1):33-49 Available from: https://bit.ly/2 BIG3GM.

22. Guchi E, Ayalew A, Dejene M, Ketema M, Asalf B, Fininsa C. Occurrence of Aspergillus species in groundnut (Arachis hypogaea L.) along the value chain in different agro-ecological zones of eastern Ethiopia. J Appl Environ Microbiol [Internet]. 2014;2(6):309-17 Available from: http://pubs.sciepub. com/jaem/2/6/7.

23. Guchi E. Effect of storage time on occurrence of Aspergillus species in groundnut (Arachis hypogaea L.) in eastern Ethiopia. J Appl Environ Microbiol [Internet]. 2015;3(1):1-5 Available from: http://pubs.sciepub.com/ jaem/3/1/1/index.html.

24. Cotty PJ, Jaime-Garcia R. Influences of climate on aflatoxin producing fungi and aflatoxin contamination. Int J Food Microbiol. 2007;119(1-2):109-15.

25. Martins LM, Sant'Ana AS, Fungaro MHP, do SJJNM d S, Frisvad JC, et al. the biodiversity of Aspergillus section Flavi and aflatoxins in the Brazilian peanut production chain. Food Res Int. 2017;94:101-7.

26. Horn BW. Colonization of wounded peanut seeds by soil fungi: selectivity for species from Aspergillus section Flavi. Mycologia. 2008;97(1):202-17.

27. Diao E, Dong H, Hou H, Zhang Z, Ji N, Ma W. Factors Influencing Aflatoxin Contamination in Before and After Harvest Peanuts : A Review. 2015;4(1): 148-54.

28. Sibakwe CB, Kasambara-donga T, Njoroge SMC, Msuku WAB, Mhango WG. The Role of Drought Stress on Aflatoxin Contamination in Groundnuts (Arachis hypogea L .) and Aspergillus flavus Population in the Soil. 2017;3(5): 22-9.

29. Horn B, W DJW. Mycological Society of America Soil populations of Aspergillus species from section Flavi along a transect through regions of the United States. 1998;90(5):767-76.

30. Dube M, Maphosa M. Prevalence of Aflatoxigenic Aspergillus spp and Groundnut Resistance in Zimbabwe. 2014;7(11):8-12.

31. Torres AM, Barros GG, Palacios SA, Chulze SN, Battilani P. Review on preand post-harvest management of peanuts to minimize a $\mathrm{fl}$ atoxin contamination. FRIN. 2014;62:11-9 Available from: https://doi.org/10.1016/j. foodres.2014.02.023.

32. Donner M, Atehnkeng J, Sikora RA, Bandyopadhyay R, Cotty PJ. Distribution of Aspergillus section Flavi in soils of maize fields in three agroecological zones of Nigeria. Soil Biol Biochem. 2009;41(1):37-44 Available from: https:// doi.org/10.1016/j.soilbio.2008.09.013.

33. Mehl HL, Jaime R, Callicott KA, Probst C, Garber NP, Ortega-Beltran A, et al. Aspergillus flavus diversity on crops and in the environment can be exploited to reduce aflatoxin exposure and improve health. Ann N Y Acad Sci. 2012;1273(1):7-17.

34. Jaime-Garcia R, Cotty PJ. Aspergillus flavus in soils and corncobs in South Texas: implications for management of aflatoxins in corn-cotton rotations. Plant Dis. 2004:88(12):1366-71.

35. Adhikari BN, Bandyopadhyay R, Cotty PJ. Degeneration of aflatoxin gene clusters in Aspergillus flavus from Africa and North America. AMB Express. 2016:1-16.

36. Hussain A, Afzal A, Irfan M, Malik KA. Turkish Journal of Agriculture - Food Science and Technology Molecular Detection of Aflatoxin Producing Strains of Aspergillus flavus from Peanut (Arachis hypogaea). 2015:3(5):335-41.

37. The National Population and housing census 2014-Area specific profiles series, Kampala. UBOS (2017). https://ubos.org/wp-content/uploads/ publications/03_2018Statistical_Abstract_2015.pdf. Accessed 22 June 2020.

38. Mutegi C, Wagacha M, Kimani J, Otieno G, Wanyama R, Hell K, et al. Incidence of aflatoxin in peanuts (Arachis hypogaea Linnaeus) from markets in Western, Nyanza and Nairobi Provinces of Kenya and related market traits. J Stored Prod Res. 2013;52:118-27 Available from: https://doi.org/10. 1016/j.jspr.2012.10.002

39. Ndungu JW, Makokha AO, Onyango CA, Mutegi CK, Wagacha JM, Christie ME. Prevalence and potential for aflatoxin contamination in groundnuts and peanut butter from farmers and traders in Nairobi and Nyanza provinces of Kenya. J Appl Biosci. 2013;65:4922-34.

40. Faustinelli PC, Palencia ER, Sobolev VS, Horn BW, Sheppard HT, Lamb MC, et al. Study of the genetic diversity of the aflatoxin biosynthesis cluster in Aspergillus section Flavi using insertion / deletion markers in peanut seeds. Mycologia. 2017;00(00):1-10 Available from: https://doi.org/10.1080/ 00275514.2017 .1307095

41. Faustinelli PC, Wang XM, Palencia ER, Arias RS. Genome sequences of eight Aspergillus flavus spp. and one a. parasiticus sp., isolated from Peanut seeds in Georgia. Genome Announc. 2016;4(2):3-4 Available from http://www. ncbi.nlm.nih.gov/pubmed/27081142.

42. Horn BW, Dorner JW. Soil populations of Aspergillus species from section Flavi along a transect through peanut-growing regions of the United States. Mycologia. 1998;90(5):767-76.

43. Christensen M. A synoptic key and evaluation of species in the Aspergillus flavus group. Mycologia. 1981;73(6):1056.

44. Geiser DM, Dorner JW, Horn BW, Taylor JW. The phylogenetics of mycotoxin and sclerotium production in Aspergillus flavus and Aspergillus oryzae. Funga Genet Biol. 2000:31(3):169-79.

45. Diba K, Rezaie S, Mahmoudi M, Kordbacheh P, Diba CK. Identification of Aspergillus species using morphological characteristics. Pakistan J Med Sci. 2007;23(6):867-72 Available from: www.pjms.com.pk.

46. Carpten JD, Smith JR, Brownstein MJ, Hu G. United States Patent ( 19 ) A / G 1. 2000;(19)

47. Arias RS, Ray JD, Mengistu A, Scheffler BE. Discriminating microsatellites from Macrophomina phaseolina and their potential association to biological functions. Plant Pathol. 2011;60(4):709-18.

\section{Publisher's Note}

Springer Nature remains neutral with regard to jurisdictional claims in published maps and institutional affiliations.

Ready to submit your research? Choose BMC and benefit from:

- fast, convenient online submission

- thorough peer review by experienced researchers in your field

- rapid publication on acceptance

- support for research data, including large and complex data types

- gold Open Access which fosters wider collaboration and increased citations

- maximum visibility for your research: over $100 \mathrm{M}$ website views per year

At BMC, research is always in progress.

Learn more biomedcentral.com/submission 